\title{
The New Zealand Police Early Intervention System: A Review of implementation and impact issues
}

\author{
Michael Briody \\ (School of Criminology and Criminal Justice,) Griffith University, Australia
}

\section{Tim Prenzler}

(School of Law and Criminology,) University of the Sunshine Coast, Australia

\begin{abstract}
This paper examines the implementation process and impacts of an Early Intervention (El) system introduced into the New Zealand Police in 2013. The system was associated with large reductions in complaints of $72.5 \%$ against target employees $(N=526)$, but without this clearly translating into reductions in the overall number of complaints. The New Zealand case also highlighted the issue of the different potential uses of early intervention. Should the priority be officer welfare or the more usual aim of improving officer conduct, police-citizen relations and public confidence in police? The authors argue that the traditional focus on reducing adverse incidents between police and citizens, with public complaints as a major guide and measure, should have at least equal weight in an Early Intervention System that is part of a comprehensive state-of-the-art police integrity management system. The paper also highlights the need for detailed publicly accessible data to ensure accountability of investments in integrity strategies.
\end{abstract}

\section{Keywords}

Complaint profiling, Early warning systems, Early Intervention Systems, police integrity management, New Zealand

\section{Introduction}

The New Zealand Police have long been recognised as attracting high levels of public support, and New Zealand is ranked amongst the most peaceful and safe countries in the world (Institute for Economics \& Peace, 2019; Rowe, 2009). Nonetheless, the department has experienced its share of scandals over the decades, including a major Commission of Inquiry from 2004 to 2007 (Bazley, 2007; Rowe, 2009). The department - with 9,482 sworn officers and 2,891 unsworn staff in 2019 - has also attracted large numbers of complaints in the last two decades, with an upward trend in recent years (New Zealand Police, 2019a, p. 138; Independent Police Conduct Authority, 2018, p. 12). Consequently, like many police departments around the world, New Zealand Police have been required to innovate in the integrity management space.

The introduction of an Early Intervention (EI) system in New Zealand in 2013 represents one major type of innovation in police integrity management. EI systems remain very much on the agenda for police around the world and are often considered to be a 'best 
practice' component of a police integrity management system (Shjarback, 2015, p. 314). IAPro - a company that sells purpose built EI systems software - reported over 50 new sales in the first eight months of 2018 and usage of its products by more than 800 'public safety agencies' around the world in 2019 (IAPro, 2018, 2019). However, evaluated case studies of EI systems in action are limited (Shjarback, 2015). Consequently, the nature of the New Zealand system and its impacts should be of interest to practitioners, researchers and policy makers committed to optimising police conduct through scientific management techniques.

\section{Literature review}

Police EI systems were introduced in the 1980s in the United States in response to findings that frequent and/or escalating complaints against individual officers were often good indicators of inappropriate and provocative conduct that became entrenched through lack of discipline or remediation - contributing to increased police-citizen conflict and reduced public trust in police (Walker et al., 2001). A legalistic case-by-case approach to complaints generally failed to pick up patterns of bad behaviour. Computer-based systems allowed police administrators to identify and monitor complaints and other indicators of potential misconduct, and to intervene with preventive measures such as counselling or retraining. More sophisticated systems set complaint thresholds against assignment types given that complaints can vary with different areas of police work (Lersch et al., 2006).

Currently, there appear to be eight case study evaluations of EI systems on the public record. Three studies in four locations have shown large reductions in complaints and other adverse indicators involving target officers subject to early intervention without showing how these affected overall rates of complaints. For example, a short exploratory study reported that in Minneapolis, 'the average number of citizen complaints received by officers subject to early intervention dropped by 67 percent one year after the intervention'; and in New Orleans, the number 'dropped by 62 percent one year after intervention' (Walker, et al., p. 3).

In a second with-in group study, in the state of Victoria Australia, the introduction of an EI system was associated with a reduction in complaints (internal and external) of $71 \%$ over two years, involving 44 officers flagged with multiple complaints (Macintyre et al., 2008). The Victorian study included financial cost-benefit data, with an estimated saving of AU\$3.2 million in reduced complaint processing costs. Of additional note in this study was a parallel programme that profiled police organisational units. Interventions in nine units were associated with a 59\% drop in complaints over one year and an estimated saving of AU\$1.4 million. The study covered the period 1997 to 2004 and, although it did not examine overall complaint numbers, subsequent research has shown large reductions in the rates of complaints against officers in Victoria in that period (Prenzler and Briody, 2018). Positive outcomes were also identified from a mentoring-based in the Los Angeles Sheriff's Department (Bobb et al., 2009). The program combined complaints with other 'risk-related incidents' for both profiling and impact assessment (p. 76). Large reductions occurred in the longer measure of three years pre-intervention and three years post-intervention, including a $51 \%$ reduction in use of force incidents, a $92 \%$ reduction in lawsuits and an $86 \%$ reduction in shootings. 
Four studies have examined the relationship between early intervention, multiple complaints and overall complaint numbers. The EI system introduced in Miami-Dade in 1981 was associated with an 84\% decline in excessive force complaints from 101 in 1980 to 16 in 1992 (Charette, 1993). The system flagged 37.5 officers per quarter on average in the first year of operation. This then fell by $80 \%$ to 7.6 per quarter, sustained over 11 years. A study of two police precincts in the Bronx in the 1990s identified reductions in citizen complaints of 54\% and 64\% over six years (Davis et al., 2005). Officers receiving multiple complaints were subject to close supervision and would meet with their precinct commanders to work out 'preventive actions' (p. 238). In more serious cases, interventions could include discipline or reassignment. In some cases, 'younger officers with attitude problems' were placed with selected more experienced officers. The EI system was buttressed by a wider departmentwide 'courtesy, professionalism and respect policy' (CPR) and 'verbal judo' training in deescalation and negotiation skills. The idea that 'civilian complaints were to be kept to a minimum' was an essential premise of the programs in the two precincts.

In a Tasmanian study, Porter et al. (2012) analysed an $87 \%$ reduction in public complaints over 12 years, including a $60 \%$ drop in the rates of assault and excessive force allegations. These reductions coincided with the roll out of a set of innovations that included an EI system, along with new de-escalation training, psychological testing of applicants, and more rigorous internal investigations and discipline. Analyses of complaints fed into the innovations. Finally, in Portland Oregon, Prenzler et al. (2016) found that the introduction of an EI system was associated with a 54\% reduction in public complaints over 14 years and a $74 \%$ reduction in excessive force allegations over 10 years. There were also large reductions in documented officer-involved shootings and use-of-force reports. Apart from the EI system, the reductions were associated with improved citizen oversight, strategic analyses of complaints, new de-escalation procedures and training, and a working relationship between the oversight agency and police focused on reducing police-citizen conflict and police use of force.

These latter four studies showed that large reductions in multiple complaints against individual officers made major contributions to the overall reductions in complaints. In the Bronx, Tasmania and Portland studies, the research indicated there was no diminution of policing activity - refuting a possible alternative explanation for the decline in complaints. Although none of the case studies involved matched control groups, the large long-term downward trends in complaints were contrasted with available data indicating the absence of trends of the same magnitude in similar precincts or departments. At the same time, the inclusion of a variety of integrity strategies complicated the issue of the effects of the systems. This is indicative of a general methodological issue in evaluating police reform: a package of overlapping and mutually reinforcing measures is considered necessary to address the complex nature and causes of police misconduct, but it also makes identification of the effects of individual measures almost impossible (Worden et al., 2013).

In contrast to the above studies, Worden, et al. (2013) examined the impact of an EI system focused on remedial training in police-citizen interactions in an un-named police department in the United States. The study deployed a control group based on variables that included complaint histories. Comparable time periods were also utilised - covering pre- and post-intervention times for the remedial group. No significant differences were identified in 
outcomes between the two groups. However, the researchers suggested that their study did not entirely discredit early intervention systems, showing instead the need for refinement, including the use of a greater variety of conduct indicators that would better identify officers likely to benefit from remedial training and/or other forms of intervention, along with better designed impact assessments (cf., Shjarback, 2015).

The available evidence shows that police departments have been moving towards the use of a variety of risk- and welfare-related measures for some time. These include injuries, sick leave, counselling, disciplinary reports, drug and alcohol test results, vehicle incidents and use of force measures, amongst others (e.g., Bobb, et al., 2009; Helsby et al., 2018). Reducing inappropriate conduct that triggers citizen complaints was always a primary function of EI systems. At the same time, the idea that early intervention could improve officer welfare, and even save careers, was recognised early on and has also become a major aim (Bobb, et al., 2009; Helsby, et al., 2018).

\section{Method}

This research project was developed initially in response to the following statement in the 2015-16 New Zealand Police Annual Report,

Uptake of the EI system has more than doubled since it was introduced - with the number of early interventions increasing from 80 in 2013 to 169 in 2015. In 2015, Police focussed on reducing the number of complaints made against police officers. All officers who had received two or more complaints in the previous 12 months were identified for EI meetings, leading to a $63 \%$ reduction in complaints received about this cohort. (New Zealand Police, 2016: 124).

The data were in line with the majority of published studies on early intervention systems and raised questions, consistent with the literature, regarding possible larger impact on complaints and specific operational aspects of the New Zealand system. Investigations were conducted of official documents available on the internet and, in July 2017, an enquiry was made to the Research and Evaluation Section of the New Zealand Police regarding possible cooperation on further research on the topic. Following advice, a formal application was submitted to the External Research Request Approval Committee in October 2018. Approval was granted in January 2019 and the researchers were referred to Inspector Matt Scoles, Early Intervention Manager, and Superintendent Anna Jackson, National Manager Police Professional Conduct. In early-May 2019, the researchers submitted a request for information to Inspector Scoles. Detailed data were requested on complaints, including allegations and numbers of multiple complaints and allegations, before and after the introduction of the EI system. Descriptive material on the operations of the system was also requested, along with the Inspector's opinion about 'what has or has not worked with the EI system - and why?'

A response was provided in the latter part of May 2019, including provision of several short reports on the operation of the system. Follow up questions were answered on an ad hoc basis. A final set of data was supplied in January 2020. The results are set out in the findings section below, combined with public source material. The latter include police annual reports, 
annual reports and other reports from the police oversight agency the Independent Police Conduct Authority, as well as a variety of other public source material. The reportage is structured below under the following headings: (1) Introduction of the New Zealand EI system, (2) Operations of the New Zealand EI system and (3) Impacts of the New Zealand EI system.

Research ethics approval 2017/69 was granted by Griffith University. The New Zealand Police contacts were provided with a final copy of the paper. One minor comment was made which was accommodated in the discussion section.

\section{Findings}

\section{Introduction of the New Zealand EI System}

The main impetus for the introduction of a national EI system for the New Zealand Police was a recommendation from the 2007 Report of the Commission of Inquiry into Police Conduct (Bazley, 2007). The Inquiry was concerned with a range of types of misconduct, including sexual misconduct. The existing police integrity system was found to be overly legalistic and sub-standard. Poor discipline and lack of monitoring of officers' behaviour were critical factors facilitating misconduct. Bazley (2007: 270) noted 'examples where police officers inappropriately remained in the police force over a period of years despite clear indicators that there were concerns about their behaviour'. As one example:

(An) officer was charged before the police disciplinary tribunal in 2000 with numerous incidents of misconduct, including making sexually offensive statements to members of the public. He had previously been the subject of a sexual harassment complaint in 1998 in which he allegedly made a sexually offensive remark to a colleague. He subsequently resigned, after having admitted three of seven charges (p. 270).

Three of the 60 recommendations arising from the Inquiry related directly to an EI system (Bazley, 2007: 21, 22):

R47 New Zealand Police should implement a nationally mandated early warning system in order to identify staff demonstrating behaviour that does not meet acceptable standards and ensure such behaviour does not continue or escalate.

R48 The early warning system should ensure that all relevant information, sufficient to give a complete picture of an officer's full record of service, is captured in a single database, and is accessible to police managers and supervisors when making appointments and monitoring performance, as well as to complaint investigators when appropriate. 
R49 New Zealand Police should review its approach to performance management, including the training provided to supervisors and managers, the performance appraisal process and documentation, and the methods in place to ensure that the follow-up identified in the performance improvement plans actually occurs.

Despite these recommendations being made in 2007, it was not until 2011 that official approval was given for the development of a force-wide system (Scoles, 2017: 2). The proposal recommended use of the dedicated EIS IAPro software application that had been in operation in the New Zealand Police since 2009 for managing complaints (New Zealand Government, 2017, pp. 30). Scoles (2017: 3) noted that:

There had also been previous versions of EI in some areas of the country and this simply added to the feelings of mistrust. One version, in particular, was managed by Professional Standards and was assessed on the number of complaints made against an individual. Once an officer hit the threshold they were summoned to a talk with the Inspector in charge of Professional Conduct. Staff hated it and it has taken some time to overcome negative views then formed of EI.

Development of the new system included setting up the IT requirements, consultation with overseas police departments about operational aspects including conduct and welfare indicators, appointment and training of 'Early Intervention Leads' in different areas of the department, appointment of an analyst, and development of a communication strategy (Scoles, 2017). The national EI system was operational in 2013, with the first case processed in February. In 2014/15 'a dedicated Early Intervention Team was established at Police National Headquarters' (New Zealand Government, 2017: 32).

\section{Operational Aspects of the New Zealand EI System}

The EI system introduced in New Zealand has been located in the employee relations section of human resources. It has been 'completely separate from Professional Standards and any disciplinary processes' (Scoles, 2017: 2). Partly as a result of the early negative experiences with a disciplinary orientation (above), the focus has been on staff welfare and confidentiality:

The information obtained and prepared for EI is confidential to the employee and the EI Lead. The information and anything that takes place within the EI environment is also confidential to EI and cannot be accessed or used by any other group or process such as performance management, appointments, or anything related to disciplinary procedures. Employees that we engage with have the ability to reveal, report, or request anything, with the confidence that it will not go any further or disadvantage them in any way. (Scoles 2017: 2)

Scoles (2019) (personal communication 20 May 2019) added that: 
Most other enforcement agencies around the world use EI as a tool to reduce complaints and this is a significant point of difference for us here in the NZP ... our response is based on a want to ensure our people's safety and well-being, rather than a want to simply reduce complaints.

Other accounts have, however, focused less on welfare and more on the EI system as a means of pre-empting conduct that would require a disciplinary response. The 2015-16 police Annual Report cited above referred to a focus 'on reducing the number of complaints made against police officers' (New Zealand Police, 2016: 124). Another official report stated that, 'The aim of the system is to use rehabilitative interventions to reduce the likelihood that police staff behave inappropriately and to deal with that behaviour before it comes to the attention of the disciplinary system or complaints process' (Controller \& Auditor-General, 2015: 24).

The EI Team consists of a national manager at inspector level, a civilian analyst, and a widely dispersed group of 'EI leads'. In 2017 there were 26 leads. These officers are selected on the basis of a key set of attributes including 'the trust and confidence of management and the employees, credibility with employees, a desire to help others, be mature and experienced, and be able to work with confidentiality' (Scoles, 2017: 5). The role is part-time with no additional remuneration. Leads are spread across a range of ranks and locations.

Another feature of the system is that it is voluntary - beyond an initial compulsory meeting where the EI report and process are discussed. Refusal to participate further does not result in 'a negative record' (Scoles, 2017: 2). Most referrals come from flags automatically raised in the database, although colleagues can also make 'peer referrals' (Scoles, 2017).

The system began by deploying 15 'indicators' of potential behaviour and welfare problems. By 2018, 22 were used, shown in Table 1. The information is fed into the database from diverse sources on a regular basis depending on their availability. Some uploads are daily, others monthly. A 'threshold alert' is triggered when an employee receives two or more complaints within 12 months (Scoles, personal communication, 20 May 2019). Although complaint numbers are a key trigger, thresholds for alerts are calibrated at different levels for different indicators. While some indicators are 'naturally, more important than others', indicators "considered to be at the "lower-level" add to the picture of an employee's performance' (Scoles, 2017: 3). Early intervention applies to both sworn and non-sworn staff, but with a lesser number of indicators for non-sworn staff. 
Table 1: Indicators in the Early Intervention System, New Zealand Police

\begin{tabular}{|l|l|}
\hline - Complaints & - Employment Investigations \\
\hline $\begin{array}{l}\text { - Serious misconduct cases (not } \\
\text { complaint) }\end{array}$ & - Serious harm incidents \\
\hline - Excessive Internet notifications & - Use of Force incidents \\
\hline - Vehicle pursuits & - Total arrests \\
\hline - Arrests with no charges & - Discretionary arrests \\
\hline - Discretionary arrests without charges & - Withdrawn Charges \\
\hline - Withdrawn discretionary charges & - Cases assigned less than 6 months \\
\hline - Cases assigned exceed 6 months & - Traffic infringement prosecutions \\
\hline - Victimisation (of employee) & - Annual Leave \\
\hline - Sick leave taken & - TOIL (overtime worked) 'Time off in lieu' \\
\hline - Physical test currency & - Mandatory training currency \\
\hline
\end{tabular}

Source: Scoles (2017: 3). Used with permission.

The core element of the intervention involves a meeting between the subject officer, their supervisor and an EI Lead. The full EI process involves the following 11 steps (Scoles, 2017: 5):

1. Identification made via database or referral

2. Statistical data gathered

3. Confidential inquiries made with supervisor of employee

4. Reports prepared

5. Case prepared in IAPro (EI at level 2, rest in level 3)

6. Case Blueteam pipelined out to EI Lead, this means it only goes to and is only seen by that person and does not feature on any other dashboards. An email to the Lead is also done so they know to check their Blueteam. ['Blueteam' refers to the electronic documentation associated with IAPro software (http://www.iapro.com/).]

7. EI Lead contacts supervisor to explain about EI and have the supervisor set up a meeting involving them, the EI Lead and the employee

8. Meeting held

9. Case updated in Blueteam and final report attached and marked complete

10. Case reviewed by EI Manager, statistical data updated, employee 'monitored' and case closed

11. Employee monitored for 12 months.

It was unclear from the information provided what types of agreements or plans were generated from meetings.

The data-based profiles used to inform referrals were described as very limited in terms of the real complexities of cases. Consequently, supervisors and EI Leads needed to exercise discretion and sensitivity to ensure the nuances of cases were appropriately addressed (Scoles, 2017: 11): 
It is clear that a hard and fast rule is not helpful in EI. For example, if you engage with an officer who has had two complaints, it may be that one complaint was against multiple officers and that the officer was not really the main one complained of, or that another complaint is frivolous and clearly vindictive. All analysis must be considered appropriately and EI staff engaging in the analysis must have the ability to 'read between the lines' on disciplinary matters and other incidents in order to do that job properly. Otherwise you risk the process losing credibility amongst your organisation's staff.

The number of interventions each year from 2013 to 2018 is shown in Figure 1. The average over the period was 135, with a sharp rise from 80 in 2013 to 169 in 2015, peaking at 206 in 2018. The large drop to 89 in 2016 was the result of the EI National Manager experiencing a protracted illness and a delay in appointing a replacement (Scoles, 2017: 10). After the first year there was an increasing number of peer referrals. This was attributed in part to increasing knowledge of the system and its welfare focus. Numbers for complaint/allegation types and other database triggers and peer referrals were not available. Separate numbers for sworn and unsworn staff were also not available. In addition, the proportions of complaints and/or allegations involving multiple complaints and/or allegations were not available beyond the following very limited accounts. Scoles (2017: 8) noted that:

NZ Police has approximately 12,000 employees. About 9000 of these are sworn officers. On average every year about 1500 receive one complaint (12.5\%). 250 receive two complaints (2\%) and about 45 receive 3 or more.

The 2015 reform assessment by the Controller and Auditor-General reported that 'the most common reason for an intervention in 2014 was complaints about the police officer $(53 \%$ of cases)' (p. 24).

\section{Figure 1: Number of Interventions per Annum, 2013-2018}

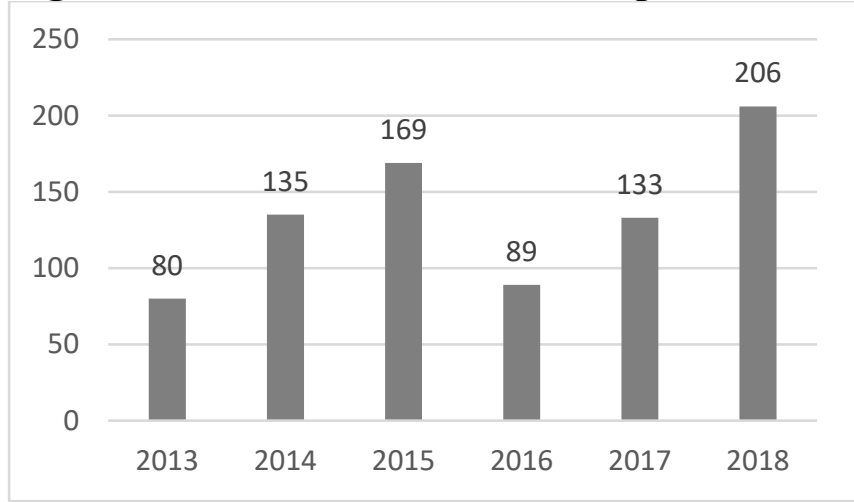

Source: Scoles, 2018, p. 8. Used with permission.

Table 2 shows the outcomes from early intervention meetings for the period up to 1 November 2018. This was the only format available for these data. Almost two-thirds involved 'no further action, with the next largest category 'welfare referrals' and 'mentoring by supervisor' at $17 \%$ each. 
Table 2: Outcomes from Early Intervention Meetings, 2013 to November 2018

\begin{tabular}{|l|c|}
\hline No further action required (following the initial meeting) & $62 \%$ \\
\hline Welfare referral & $17 \%$ \\
\hline Mentoring by supervisor & $17 \%$ \\
\hline Change of duties & $3 \%$ \\
\hline Further training & $1 \%$ \\
\hline
\end{tabular}

Source: Scoles, 2018, p. 9. Used with permission.

Ongoing promotion of the system occurs through departmental and union magazines and addresses to in-service training courses (Scoles, 2017). The EI Leads also promote the system by talking to staff in their areas and encouraging participation (Scoles, 2018).

\section{Impact of the New Zealand EI System}

The Government's ten-year implementation report on the Commission of Inquiry recommendations (above) referred to 'an effective system for early identification and supportive informal intervention on behaviour that could escalate' (New Zealand Government, 2017: 6). This was despite the complete absence of data on the topic in the report. The method section above referred to a statement in the 2015-16 New Zealand Police Annual Report that there had been a 63\% reduction in complaints against officers who had participated in the system in the preceding 12 months - although the number of officers involved and types of complaints were not specified (New Zealand Police, 2016: 124).

The most comprehensive impact data supplied by the New Zealand Police for the present study are shown in Table 3, for interventions conducted in the years 2014 to 2017, comparing complaints against officers who experienced the EI process 12 months before and 12 months after. The table shows an overall reduction of $72.5 \%$ from 910 down to 250 when complaint numbers in the 12 months prior to the EI engagement were compared to numbers in the 12 months post engagement. A 'significant reduction in sick leave' by those staff was also recorded (Scoles, 2018: 9). More generally, according to Scoles (2017: 11):

Early Intervention in the New Zealand Police is proving to be very successful in helping staff that have issues and need help in both work and personal life. Several people have provided feedback that they believed their career had been saved, following EI engagement.

According to the 2015 report on the implementation of the Commission of Inquiry recommendations (Controller \& Auditor-General, 2015: 25):

The Police surveyed staff who have had an early intervention and found that four fifths of respondents were positive about the experience. We also heard of staff members with stress in their personal lives who welcomed the intervention. 
Table 3: Pre- and Post- Complaint Numbers, 12 Months, for EIS Cohorts 2014 to 2017

\begin{tabular}{|c|l|l|l|l|}
\hline Year & $\begin{array}{l}\text { Number of officers } \\
\text { subject to Early } \\
\text { Intervention }\end{array}$ & $\begin{array}{l}\text { Complaints for } \\
\text { group 12 months } \\
\text { prior to Early } \\
\text { Intervention }\end{array}$ & $\begin{array}{l}\text { Complaints for } \\
\text { group 12 months } \\
\text { following Early } \\
\text { Intervention }\end{array}$ & $\begin{array}{l}\text { Percentage } \\
\text { Change }\end{array}$ \\
\hline 2014 & 135 & 277 & 78 & -71.8 \\
\hline 2015 & 169 & 288 & 58 & -79.1 \\
\hline 2016 & 89 & 161 & 29 & -81.9 \\
\hline 2017 & 133 & 184 & 85 & -53.8 \\
\hline Total & 526 & 910 & 250 & -72.5 \\
\hline
\end{tabular}

Source: New Zealand Police, 23 January 2020. Used with permission.

The reductions in complaints against officers subject to early intervention did not clearly translate into reductions in overall complaint numbers - although the available data are highly problematic. The IPCA is the only source for long-term complaints data. Figure 2 shows that these increased following the introduction of the EI system in 2013. Complaint numbers in 2012/13 and 2013/14 averaged 2,095, and these increased by $21 \%$ to an average 2,541 over the following four years. However, as with the complaint numbers in Table 3 , these data do not disaggregate complaints against sworn and unsworn staff and do not disaggregate internal and public complaints. The latter are available as 'external complaints' from 2014, after the introduction of the EI system, published by the New Zealand Police and reported in Figure 3. These show a slight downward trend beginning in 2016.

Figure 2: Total Number of Complaints, New Zealand Police, 2004/05 to 2017/18

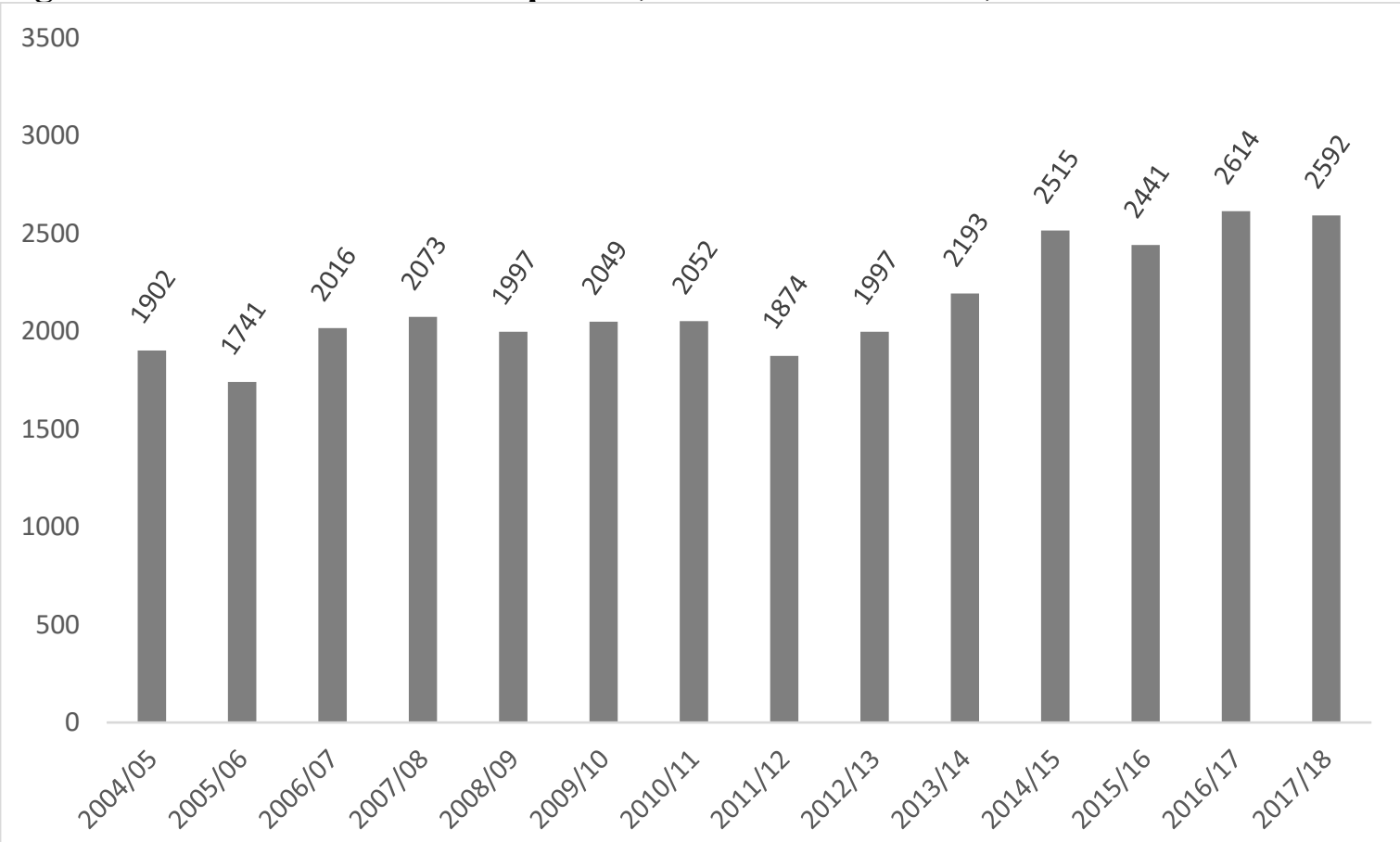

Source: Independent Police Conduct Authority (2012: 10; 2018: 12). 
Figure 3: Number of External Complaints, New Zealand Police, 2014 to 2018

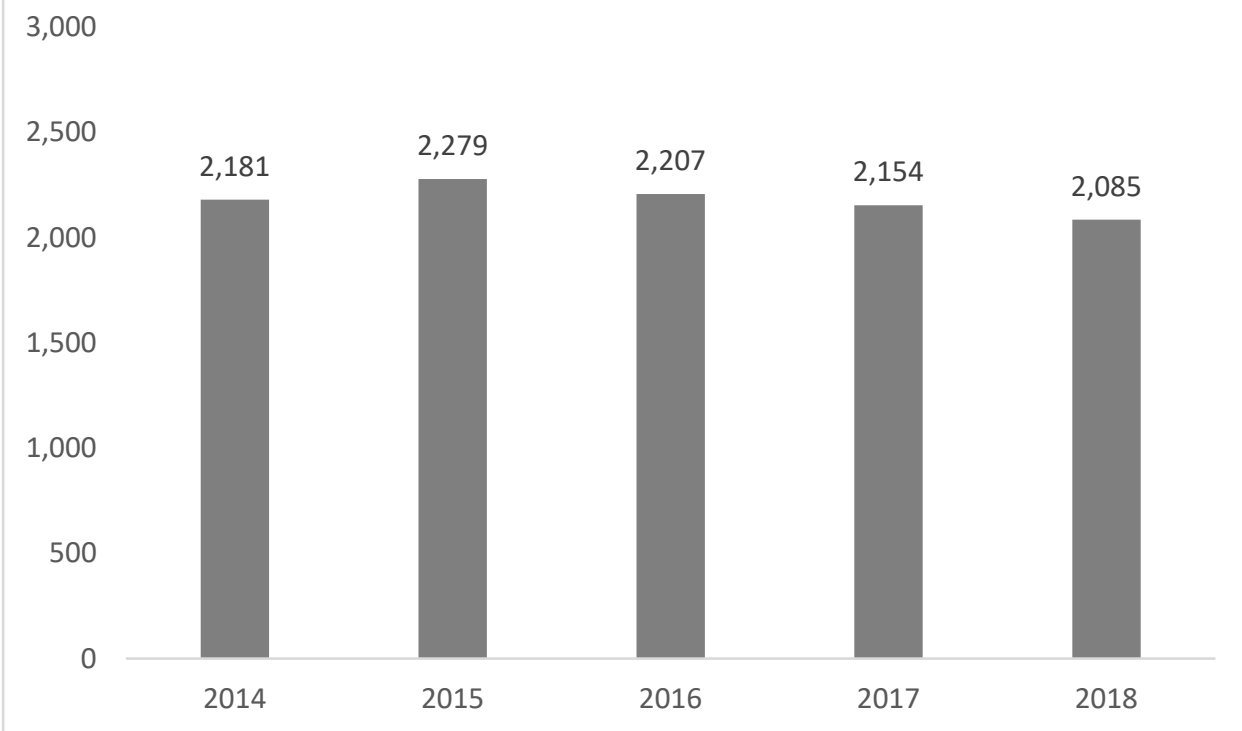

Source: New Zealand Police (2019c: 1).

Police reported use of force numbers have been published since 2014. Comparable data are not available from before the introduction of the EI system in 2013 and, as indicated, the EI data do not separate out use of force complaints. The available use of force data are termed 'TOR events', or 'Tactical Options Reports', covering 'Handcuffs \& Restraints; OC Spray; Empty Hand; Baton; Dog; TASER; Firearm' (New Zealand Police, 2018: 1, 2). Table 4 shows a moderate increase from 2014 to 2016 followed by a moderate decline. Finally, public opinion survey results regarding trust and confidence in the police, beginning in 2008/09 and reported in Figure 4, showed no apparent positive influence from the EI system.

Table 4. Number of Reported Use of Force Incidents by New Zealand Police, 2014 to 2018

\begin{tabular}{|l|r|r|r|r|r|}
\hline Year & 2014 & 2015 & 2016 & 2017 & 2018 \\
\hline Use of force events & 4,823 & 4,914 & 5,055 & 4,536 & 4,398 \\
\hline
\end{tabular}

Source: New Zealand Police (2019d). 
Figure 4: Public Opinion Survey Results, Percent with 'Full/Quite a Lot of Trust \& Confidence in Police', 2008/09 to 2017/18

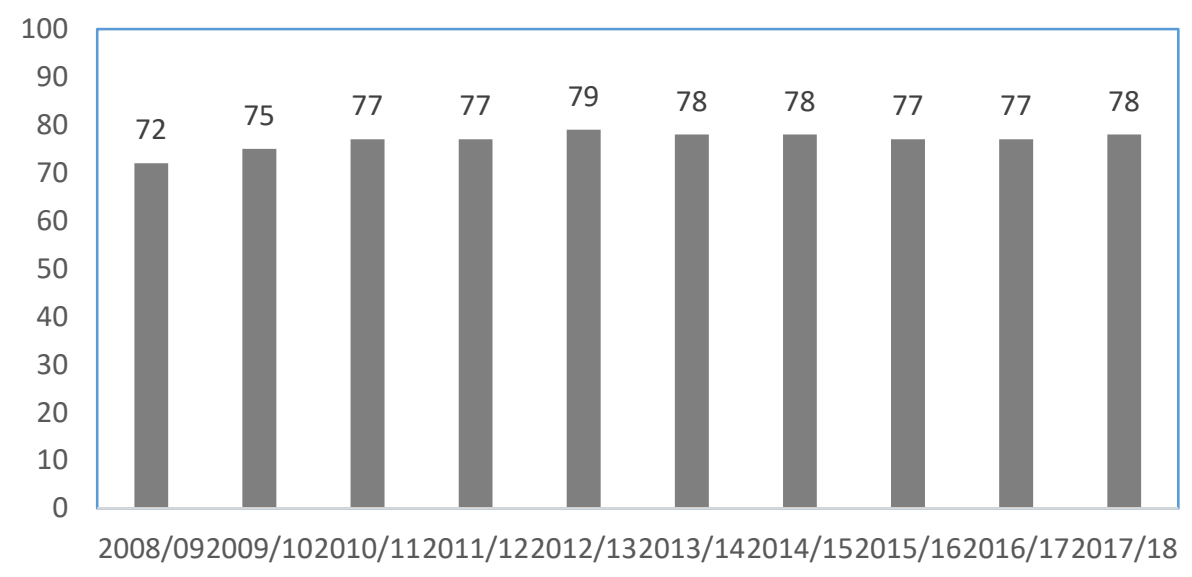

Source: New Zealand Police (2019b).

\section{Discussion}

This study of the introduction of an EI system in the New Zealand Police highlighted many of the same issues apparent in other documented cases. In the first place, the idea for mainstreaming EI came out of a crisis in police integrity (cf., Prenzler, et al., 2016). In the New Zealand case, the EI system was part of a package of reforms imposed on the police from the outside. Additionally, as is often the case in police organisations, implementation of reform was slow and halting and limited in reach. Nonetheless, once it was up and running, the New Zealand EI system was associated with large reductions in complaints against participating employees, consistent with the majority of case studies in the literature. Unfortunately, however, unlike some other studies, there was no clear flow through effect to overall complaint numbers and use of force data.

Explaining this complexity is difficult. One likely explanation is that the number of complaints involving multiple complaints against a single officer has been too small in the New Zealand case for a general benefit from the EI system and/or that the interventions have been too small in number to counter the drivers of increasing complaints. The annual total number of complaints and the annual number of complaints involving early intervention were given in different formats (Table 3 and Figure 2). However, in very approximate terms, only $9 \%$ of complaints were subject to early intervention in the four years from 2014 to 2017.

The police oversight agency, the Independent Police Conduct Authority, has referred to increases in the both the volume and complexity of complaints, indicating resource constraints in responding appropriately (2017: 5). The 2014/15 Annual Report speculated that the surge in complaints 'can be attributed in part to the efforts that have been made to increase the visibility and public recognition of the role we play. It might also reflect increasing public confidence in the effectiveness of our work' (Independent Police Conduct Authority, 2015: 13). Nonetheless, New Zealand Police, like many police departments, have a long history of self-policing, and civilian control of the complaints and discipline system is still extremely limited, suggesting the possible continuation or escalation of a culture of perceived impunity or partial impunity (Buttle \& Deckert, 2017; den Heyer \& Beckley, 2016; 
Rowe, 2009). For example, the Independent Police Conduct Authority investigated just 2.7\% of complaints in 2016-17 and 2017-18, and the agency has no adjudicative authority (Independent Police Conduct Authority, 2017: 4: 2018: 5, 10).

The issue of explaining complaint trends also involves a problem of inadequate accountability and transparency. Long-term complaint data are not published as a rate per number of officers and, although 'common complaint types' have been reported numerically by the Independent Police Conduct Authority since 2012-13 (e.g., Independent Police Conduct Authority, 2018: 14), this is not done in a way that allows for long-term trends to be identified. Furthermore, the internal data on subject officers obtained for this study were limited to one year before and after early intervention. As a result, the sustainability of the system's effects was not assessable.

Also, as noted, available long-term published complaints data combine public complaints and internal complaints. Consequently, it might have been the case that public complaints declined while internal complaints increased, as has occurred elsewhere (Porter, et al., 2012). There was some evidence that this might have occurred in the latter years, as shown in Figure 3 for available 'external complaints'. It is possible that increased internal reporting was influenced by a Commission of Inquiry reform measure to encourage staff disclosures, including providing a more rigorous investigative response. A better response to internal disclosures was framed in the following terms in the 2017 ten-year review of the implementation of the Commission of Inquiry recommendations (New Zealand Government, 2017: 11):

Internally and externally, trust and confidence in Police can be influenced by how well complaints by the public about Police staff, and by Police staff about their colleagues, are managed and investigated. Police staff have always called out inappropriate behaviour by their colleagues. However, willingness to do this has been variable influenced by perceptions of how certain colleagues have been 'protected' by other staff, and whether those colleagues have been on the receiving end of uncomfortable informal behaviour when previous complaints have been made.

It might also be the case that the New Zealand Police have been over-reliant on voluntary participation in the EI system and the separation of the system from disciplinary processes. Furthermore, the more apparently successful EI programs outlined in the literature review operated as part of explicit complaint reduction programs that involved a variety of other documented interventions which followed closely from complaint analyses, including de-escalation training and procedural changes to use of force. The present study has shown that the New Zealand Police face a range of challenging conduct issues. Trust and confidence measures have averaged $77 \%$ in the last ten years. This is a very good outcome viewed in an international context (Ortiz-Ospina and Roser, 2016). However, there is still a substantial proportion of the population that feel alienated from police and, despite the inherently adversarial nature of the relationship between police and some members of the community, there might be room for improvement given higher indicators of trust and confidence in police and police integrity in some other jurisdictions (Ortiz-Ospina and Roser, 2016; Prenzler \& Briody, 2018). Of additional importance is the fact that formal complaints are 
widely considered to represent just the tip of the iceberg of public dissatisfaction with police actions (Porter, et al., 2012).

The 2017 ten-year review of the implementation of the Commission of Inquiry recommendations noted the introduction of a number of measures beyond the EI system, including enlarged civilian oversight, more rigorous complaint investigations and discipline, easier complaints lodgements, encouragements for internal reporting (above), enhanced ethics training and diversity in recruitment (New Zealand Government, 2017). In theory, as the IPCA argued, improvements to a complaints system will encourage more complaints as confidence in the system increases. However, complaints should then begin to trend down as behavioural change mechanisms start to take effect. So far, this does not appear to have occurred, although, as indicated, one of the problems in making this assessment is that reportage of complaints does not differentiate between internal complaints and public complaints over the long-term.

Overall then, there appears to be a case for the introduction of a larger set of police integrity management strategies in New Zealand, including enlargement of the EI system. Scoles (2017: 11) noted that, 'given more resources, there is ample evidence to suggest that we [the EI Team] could achieve much more and there is real opportunity to assist employees to become more engaged and more motivated to succeed'. This could include profiling and interventions with police organisational units (cf., Macintyre, et al., 2008). This then leads to the main contribution of the present paper in highlighting the potential benefits of early intervention systems as an essential part of a comprehensive integrity management program. In the New Zealand case, as with many police departments, consideration could also be given to integrity testing, drug and alcohol testing, and body worn cameras, to name a few key strategies (e.g., Ariel et al., 2017). In 2018, New Zealand Police stated that they would monitor developments in body worn cameras but had no plans to introduce them (Dynon, 2018; Vance, 2019).

The overall message - in addressing the need in most jurisdictions to improve policecitizen relations and trust and confidence in police - is that more use should also be made of diagnostics. Internal ethical climate surveys and arrestee surveys provide valuable data to address areas of police conduct that might be improved, as do regular public perception and experience surveys, and detailed surveys of all complainants and officers who are the subject of complaints (Prenzler \& Briody, 2018). Surveys of all participants in the EI process could help to provide more evidence about its impacts and ways of optimising impacts. There is also evidence that face-to-face complainant-officer mediation assists in the resolution of complaints, and in officers' understanding of the impacts of their conduct and willingness to change (Schaible, de Angelis, Wolf \& Rosenthal, 2013).

\section{Conclusion}

With the introduction of an Early Intervention system in the New Zealand Police, a 72.5\% reduction in complaints against a cohort of officers was identified when complaints in the 12 months before the EI system was applied were compared with those in the 12 months following. However, trends in other indicators, including complaints and public confidence, have not been as positive. In addition, there was a lack of detail in the complaints data in 
terms of categories of complaints, numbers of repeat complaints over multiple years, sources of complaints and targets of complaints. EI systems involve a considerable investment of public resources, and public accountability requires detailed data to assess the value of the investment. An additional lesson from this study is that improvements in police conduct will most likely require a much wider range of integrity management strategies that work in conjunction with an EI system.

\section{Acknowledgements}

The authors would like to express their gratitude to Inspectors Matthew Scoles and Donna Laban, and Ms Lillian Mapu, of the New Zealand Police for their generous assistance with this project.

\section{References}

Ariel, B., Sutherland, A., Henstock, D., Young, J., Drover, P., Sykes, J., Megicks, S. and Henderson, R. (2017). 'Contagious accountability': A global multisite randomized controlled trial on the effect of police body-worn cameras on citizens' complaints against the police. Criminal Justice and Behavior, 44(2), 293-316.

Bazley, M. (2007). Report of the Commission of Inquiry into Police Conduct. Wellington, New Zealand: Commission of Inquiry into Police Conduct.

Bobb, M. J., Barge, M., Mazar, Y., Naguib, C. and Shugrue, T. (2009). Los Angeles County Sheriff's Department: $27^{\text {th }}$ semiannual report. Los Angeles: Police Assessment Resource Center.

Buttle, J. and Deckert, A. (2017). The police complaints process. In A. Deckert \& R. Sarre (Eds.), The Australian and New Zealand handbook of criminology, crime and justice (pp. pp. 269-283). London: Routledge.

Charette, B. (1993). Early identification of police brutality and misconduct: The Metro-Dade Police Department model. Retrieved from

http://www.fdle.state.fl.us/FCJEI/Programs/SLP/Documents/Abstract/Charette

Controller and Auditor-General. (2015). Response of the New Zealand Police to the Commission of Inquiry into Police Conduct: Fourth monitoring report. Wellington: Author.

Davis, R., Mateu-Gelabert, P. and Miller, J. (2005). Can effective policing also be respectful? Police Quarterly, 8(2), 229-247.

den Heyer, G. and Beckley, A. (2016). Police oversight in Australia and New Zealand. In T. Prenzler \& G. den Heyer (Eds.), Civilian oversight of police: Advancing accountability in law enforcement (pp. 205-225). Boca Raton: CRC Press - Taylor \& Francis.

Dynon, N. (2018). Will New Zealand Police adopt body-worn cameras? Retrieved from http://www.defsecmedia.co.nz/physical-security/apr-2018-body-worn-cameras/ accessed 28 January 2019.

Helsby, J., Carton, S., Joseph, K., Mahmud, A., Park, Y., Navarrete, A. and Ghani, R. (2018). Early intervention systems: Predicting adverse interactions between police and the public. Criminal Justice Policy Review, 29(2), 190-209. 
IAPro. (2018). Record number of new adopters in 2018, including one of the largest police forces in the world. Retrieved from http://www.iapro.com/2018/08/30/record-numberof-new-adopters-in-2018-including-one-of-the-largest-police-forces-in-the-world/ accessed 19 October 2019.

IAPro. (2019). Product history. Retrieved from http://www.iapro.com/about/product-history/ accessed 28 January 2020.

Independent Police Conduct Authority. (2012). Annual report 2011 - 2012. Wellington: Author.

Independent Police Conduct Authority. (2015). Annual report 2014 - 2015. Wellington: Author.

Independent Police Conduct Authority. (2017). Annual report 2016 - 2017. Wellington: Author.

Independent Police Conduct Authority. (2018). Annual report 2017 - 2018. Wellington: Author.

Institute for Economics and Peace. (2019). Global Peace Index 2019. Retrieved from http://visionofhumanity.org/app/uploads/2019/06/GPI-2019-web003.pdf accessed 19 October 2019.

Lersch, K. M., Bazley, T. and Mieczkowski, T. (2006). Early intervention programs: An effective police accountability tool, or punishment of the productive? Policing: An International Journal of Police Strategies and Management, 29(1), 58-76.

Macintyre, S., Prenzler, T. and Chapman, J. (2008). Early intervention to reduce complaints: An Australian Victoria Police initiative. International Journal of Police Science and Management, 10(2), 238-250.

New Zealand Government. (2017). A decade of change, 2007-2017: Implementing the recommendations of the Commission of Inquiry into Police Conduct. Wellington: Author.

New Zealand Police. (2016). Annual report 2015/16. Wellington: Author.

New Zealand Police. (2018). New Zealand Police tactical options research report 2018. Wellington: Author.

New Zealand Police. (2019a). Annual report 2018/19. Wellington: Author.

New Zealand Police. (2019b). Citizens' satisfaction survey reports. Retrieved from https://www.police.govt.nz/about-us/publication/citizens-satisfaction-survey-reports accessed 22 October 2019.

New Zealand Police. (2019c). Tactical options research reports. Retrieved from https://www.police.govt.nz/about-us/publication/tactical-options-research-reports accessed 24 October 2019.

New Zealand Police. (2019d). Total incidents received for the last 5 calendar years. Retrieved from https://www.police.govt.nz/about-us/about-new-zealand-police/policeprofessional-conduct/professional-conduct-statistics accessed 24 October 2019.

Ortiz-Ospina, E. and Roser, M. (2016) Trust. Available at: https://ourworldindata.org/trust accessed 18 March 2020.

Porter, L. E., Prenzler, T. and Fleming, J. (2012). Complaint reduction in the Tasmania Police. Policing and Society: An International Journal of Research and Policy, 22(4), 426-447. 
Prenzler, T. and Briody, M. (2018). Complaint reduction in Australian federal policing in the Australian Capital Territory. Police Practice \& Research: An International Journal, 19(5), 413-426.

Prenzler, T., Cawthray, T., Porter, L. E. and Alpert, G. P. (2016). Reducing public complaints and use of force: The Portland Police Bureau experience. Journal of Criminological Research, Policy and Practice, 2(4), 260-273.

Rowe, M. (2009). Notes on a scandal: The official enquiry into deviance and corruption in New Zealand police. Australian \& New Zealand Journal of Criminology, 42(1), 123 138.

Schaible, L. M., De Angelis, J., Wolf, B. and Rosenthal, R. (2012). Denver's citizen/police complaint mediation program: Officer and complainant satisfaction. Criminal Justice Policy Review, 24(5), 626-650.

Scoles, M. (2017). New Zealand Police - Early Intervention. Wellington: New Zealand Police.

Scoles, M. (2018, November 13-15). Early Intervention (EI): New Zealand Police. Paper presented at the IAPro Users Conference, San Diego.

Scoles, M. (2019). Personal Communications, 13 February and 20 May 2019.

Shjarback, J. A. (2015). Emerging early intervention systems: An agency-specific pre-post comparison of formal citizen complaints of use of force. Policing, 9(4), 314-325

Vance, A., 2019. New Zealand Police halt review into adopting body cameras, online at https://www.stuff.co.nz/national/crime/112448221/new-zealand-police-halt-reviewinto-adopting-body-cameras accessed 23 October 2019.

Walker, S., Alpert, G. and Kenney, D. (2001). Early warning systems: responding to the problem police officer. Washington, DC: National Institute of Justice.

Worden, R., Kim, M., Harris, C., Pratte, M., Dorn, S. and Hyland, S. (2013). Intervention with problem officers: An outcome evaluation of an EIS intervention. Criminal Justice and Behavior, 40(4), 409-437. 